\title{
Assessing the Economic Value of Co-Optimized Grid-Scale Energy Storage Investments in Supporting High Renewable Portfolio Standards
}

\author{
Roderick S. Go ${ }^{\mathrm{a}, \mathrm{c}, *}$, Francisco D. Munoz ${ }^{\mathrm{b}}$, Jean-Paul Watson ${ }^{\mathrm{c}}$ \\ ${ }^{a}$ Johns Hopkins University, Baltimore, MD 21218 \\ ${ }^{b}$ Universidad Adolfo Ibáñez, Santiago, Chile \\ ${ }^{c}$ Sandia National Laboratories, Albuquerque, NM 87123
}

\begin{abstract}
Worldwide, environmental regulations such as Renewable Portfolio Standards (RPSs) are being broadly adopted to promote renewable energy investments. With corresponding increases in renewable energy deployments, there is growing interest in grid-scale energy storage systems (ESS) to provide the flexibility needed to efficiently deliver renewable power to consumers. Our contribution in this paper is to introduce a unified generation, transmission, and bulk ESS expansion planning model subject to an RPS constraint, formulated as a two-stage stochastic mixed-integer linear program (MILP) optimization model, which we then use to study the impact of co-optimization and evaluate the economic interaction between investments in these three classes of assets in achieving high renewables penetrations. We present numerical case studies using the 24-bus IEEE RTS-96 test system considering wind and solar as available renewable energy resources, and demonstrate that up to $\$ 180$ million/yr in total cost savings can result from the co-optimization of all three assets, relative to a situation in which no ESS investment options are available. Surprisingly, we find that co-optimized bulk ESS investments provide significant economic value through investment deferrals in transmission and generation capacity, but very little

\footnotetext{
* Corresponding author

Email addresses: rgo@jhu.edu (Roderick S. Go), fdmunoz@uai.cl (Francisco D. Munoz),
} jwatson@sandia.gov (Jean-Paul Watson)
\end{abstract}

Preprint submitted to Applied Energy

July 30, 2016

(C) 2016. This manuscript version is made available under the Elsevier user license http://www.elsevier.com/open-access/userlicense/1.0/ 
cost savings in operational cost. Finally, we observe that planning transmission and generation infrastructure first and later optimizing ESS investments - as is common in industry - captures at most 1.7\% (\$3 million/yr) of the savings that result from co-optimizing all assets simultaneously.

Keywords: Energy storage, Renewable portfolio standards, Transmission expansion planning

2010 MSC: 00-01, 99-00

\section{Introduction}

The electricity industry is undergoing significant transformation due to increasing renewables generation. At the end of 2014, renewables represented nearly $60 \%$ of global generation capacity additions, reaching a total installed 5 capacity of $1,712 \mathrm{GW}$ [1]. To continue reducing emissions and promoting investment in new renewable generation (from wind and solar), environmental regulators are increasingly relying on new integration technologies, such as energy storage systems (ESS), and incentives, such as Renewable Portfolio Standards (RPSs), Feed-In Tariffs (FITs), and Investment and Production Tax Credits

10 (ITCs and PTCs) 2]. To date, more than 150 countries have implemented renewable policy targets [1. In this article, we focus on the interaction between RPS-type policies and generation, transmission, and ESS investments; however, our model can be extended to study interactions with other renewable environmental policies.

In contrast to other incentives that pay a fixed price for renewable generation or investment, an RPS incentivizes generators within a region to produce a minimum fraction of electricity from qualifying renewable resources via a market mechanism. Under an RPS, qualifying renewable energy is linked to a tradable Renewable Energy Certificate (REC), with generators meeting the mandate 20 by holding the equivalent number of RECs. A market provides flexibility for generators to trade these RECs to meet RPS requirements, creating economic incentives for innovative and cost-effective renewable production. 
While there is no federal-level RPS in the US, 33 states have introduced individual mandates ranging from as low as 10\% to as high as 50\% (California) and 100\% (Hawaii) [2, 3. Other countries that also have similar binding renewable mandates with tradable RECs include Australia (20\% by 2020), Chile (20\% by 2025$)$, Denmark ( $50 \%$ by 2020 ), France ( $27 \%$ by 2020$)$, Japan ( $20 \%$ by 2030), Malaysia ( $15 \%$ by 2050), Spain (38.1\% by 2020), South Africa (9\% by 2030), and Ukraine (20\% by 2030) [1. Across these countries, REC markets can vary significantly in the definition of obligations and eligibility, resource-specific set-asides and multipliers, cost caps, and available flexibility mechanisms (e.g., banking and borrowing of RECs) [4, 5]. In the US, several studies find that states that have implemented this policy effectively increased renewable investment relative to neighboring states without RPS goals [5, 6]. Other international studies find that RPSs are either about the same or marginally less effective than alternatives such as FITs [7, 8, 9].

With increasingly stringent RPS requirements come integration challenges that must be accounted for when making planning decisions. In particular, resource intermittency for wind and solar deployment can leave to over-generation and steep ramps during peak hours, as illustrated by the California ISO's nowfamous "duck curve" plot for net system demand [10]. To balance intermittent generation, operators will need to cycle thermal generators more often and deploy new flexibility resources, such as demand-side management, sub-hourly dispatch, regional coordination. Several studies argue that these operational re45 sources represent the best value for renewables integration below $50 \%$ [11, 12]; however, it is clear that operational changes alone cannot achieve the balancing needed at very high RPS levels and that investment into new network infrastructure will need to be considered.

While pumped-hydro storage remains one of the lowest cost bulk ESS technologies in terms of MWh stored, faster-responding technologies such as flywheels, super capacitors, and batteries (e.g., lithium-ion, vanadium redox flow, zinc-air, and sodium-sulfur) can provide power and ancillary services that reinforce grid stability 13 . Third party investment has also been boosted by Federal 
Energy Regulatory Commission Order No. 755 and subsequent Order No. 784, which require creation of a market for "fast and accurate" frequency regulation services for third party merchants, which is favorable for fast-responding ESS technologies [14, 15]. In this paper, however, we focus specifically on bulk energy storage services, which include load shifting, peak shaving, and generation and transmission investment deferrals [16].

Currently, the PJM Interconnection (US) has invested in over $100 \mathrm{MW}$ of battery energy storage for frequency regulation, while the Sistema Interconectado del Norte Grande (Chile) has installed over $30 \mathrm{MW}$ for the similar use [17. Further, the California Public Utilities Commission has mandated that the state's three major utilities invest in a combined 1,325 MW of energy storage capacity by 2020 [18. The specific justification for this mandate is that energy storage can improve the cost-effectiveness of integrating increasing amounts of renewables to meet the state's RPS goals - and with lower carbon emissions [19]-through 1) load shifting; 2) generation, transmission, and distribution support and upgrade deferrals; and 3) ancillary grid services [20.

While lawmakers and system planners agree that ESS investment is key to achieving high RPS targets, we find that no existing studies focus on the co-optimization of generation, transmission, and ESS investments in the face of such requirements. To address this, this paper analyzes the economic interaction between investments in these three asset categories on a synthetic transmission network for a wide range of RPS targets. We formulate our model as a two-stage stochastic mixed-integer linear program (MILP) based on standard economic dispatch and transmission expansion planning models, coupled with a generic ESS operations model. We then obtain insight into the value of ESS investments relative to other assets in achieving RPS compliance in a cost-effective manner.

Using a 24-bus test-case we find that co-optimizing generation, transmission, and ESS investments can save up to $\$ 180$ million/yr or $9.1 \%$ of total system cost with respect to a co-optimization model that does not considers ESS. Furthermore, we compare the benefits of considering ESS when optimizing transmission and generation infrastructure versus planning ESS investments after transmis- 
sion and generation infrastructure has already been selected. These savings are of (at most) $\$ 3$ million/yr instead of $\$ 180$ million/yr. Although the magnitude of these savings is not general and depends on the specific application, our results highlight that:

a) the savings that result from considering ESS investments can be significant and are primarily a result of deferrals in new generation and transmission infrastructure,

b) optimizing ESS investments after planning generation and transmission infrastructure only captures energy arbitrage value, which is a small percentage of the potential economic benefits of ESS in meeting RPS policies, and

c) co-optimization models and/or more coordination between transmission planners and investors in generation and ESS could reduce the cost of meeting RPS policies.

The rest of the paper is organized as follows. Section 2 summarizes the relevant literature on generation, transmission, and storage investment planning and in co-optimization models. In Section 3 , we propose a planning model that co-optimizes generation, transmission, and ESS investments. Section 4 describe sthe test-case and data assumptions. In Section 5 we present an analyze our numerical experiments. Finally, in Section 6, we conclude and discuss the policy implications.

\section{Literature Review}

Optimal generation and transmission investment planning has received increasing attention in the last two decades [21, 22]. Transmission planning, in particular, is a challenging problem given the combinatorial nature of the problem and the size of real-world transmission networks. Some proposed models include linearized DC mixed-integer linear formulations [23, 24], non-linear models 
with DC power flows that take into account transmission losses [25, and nonlinear models with $\mathrm{AC}$ power flows [26, 27]. In the context of power system economics, previous studies have analyzed the interaction between RPS goals, the representation of transmission constraints, and the "lumpiness" of real transmission investments, finding significantly deviations in decision-making when the physical and economic constraints are considered [28, 29, 30]. In our research we work with a linearized DC formulation, which provides a good balance between solution accuracy and computational complexity.

The majority of the investment planning models reported in the academic literature seek to minimize total system cost, assuming that the planning is done by a vertically integrated utility. However, there is another class of planning tools that fall into the category of equilibrium models. These include generation equilibrium [31], transmission-generation leader-follower schemes [32, 33, and equilibrium models with risk-averse agents [34, 35]. In this article, however, we focus on Integrated Resource Planning (IRP) approaches that can be formulated as either linear or mixed-integer linear programs. Note that if transmission is centrally planned and anticipative ${ }^{1}$ and there is perfect competition among generation firms, then the solution found using an IRP approach is equivalent to the one obtained from an equilibrium model ${ }^{2}$

With increasing interest in ESS, various studies have attempted to quantify the operational benefits of ESS on transmission networks. Both [16] and [36] find that ESS can provide significant operational savings with respect to unit 135 commitment and cycling costs. The authors of [37] extend this co-optimization model to include N-1 security criteria in a two-stage stochastic framework, finding that lower-cost investments in ESS may be favored over expensive transmission upgrade commitments. Previous work has also considered the impact

\footnotetext{
${ }^{1} \mathrm{~A}$ proactive or anticipative transmission planner makes transmission investments taking into account the effect of these upgrades on generation investments and, ultimately, on total system cost or social welfare 32 .

${ }^{2}$ This is true for perfectly competitive markets with risk-neutral agents. An extension of this result for risk-averse agents is proposed in [34].
} 
of ESS to enforce N-1 reliability criteria [36]. Finally, 38] and [39] find that ESS co-located with renewable generation can increase transmission utilization by reducing the variability of renewables output. However, 38, finds that ESS can provide increased economic value by co-location with load. While in many cases adding ESS can increase social welfare, [40] demonstrate situations in which adding ESS to an imperfect market may actually decrease social welfare.

Looking toward long-term investments, optimal ESS allocation becomes an integral component of the transmission and generation expansion planning problem. Various studies have demonstrated economic benefits from load shifting and transmission investment deferrals, the degree being dependent on the capital cost of ESS [41, 42, 43. The authors of [39] further extend this research by studying the economic value of ESS for sub-hourly dispatch, analyzing power and energy services provided by fast-responding ESS. Another study notes that the opportunity to recover investment costs through energy arbitrage alone is limited, by analyzing a model that considers both energy and ancillary services 44. This particular study demonstrates that investment in bulk ESS can provide savings in a unit commitment context through reduced thermal cycling, flattening of locational marginal prices (LMPs), and the possibility of crossmarket arbitrage (between energy and ancillary service). In 45] the authors also look at the value of energy arbitrage for ESS in European markets, concluding that this technology can provide more economic benefits in less integrated electricity markets.

However, to the best of our knowledge, there is no existing study on the interaction between generation, transmission, and ESS investments and RPS policies. More specifically, no one has assessed the value of optimizing all these assets simultaneously versus optimizing them sequentially. 


\section{Methodology}

\subsection{Nomenclature}

We now present the nomenclature for our stochastic expansion planning model with ESS.

\subsubsection{Sets and Indices}

$\mathcal{T} \quad$ Hours in a day, indexed by $t$

$\mathcal{B} \quad$ Buses, indexed by $b, b$ '

$\mathcal{G} \quad$ All generators, indexed by $g$

$\mathcal{E} \quad$ Existing generators, $\mathcal{E} \subseteq \mathcal{G}$, indexed by $e$

$\mathcal{N} \quad$ New generators, $\mathcal{N} \subseteq \mathcal{G}$ and $\mathcal{N}=\mathcal{E}^{c}$, indexed by $n$

$\mathcal{R} \quad$ New renewable generators, $\mathcal{R} \subseteq \mathcal{N}$, indexed by $r$

$\mathcal{L} \quad$ All transmission lines, indexed by $l$

$\mathcal{J} \quad$ New transmission lines, $\mathcal{J} \subseteq \mathcal{L}$, indexed by $j$

$\mathcal{S} \quad$ Joint load and renewables production scenarios, indexed by $s$

3.1.2. Parameters

$C_{n}^{i n v} \quad$ Generator investment cost $[\$ / \mathrm{MW}-\mathrm{yr}]$

$C_{g}^{\text {fom }} \quad$ Generator fixed O\&M cost [ $\$ / \mathrm{MW}$ installed]

$C_{g}^{v o m}$ Generator variable O\&M cost [\$/MWh]

$C_{g}^{\text {fuel }} \quad$ Fuel cost $[\$ / \mathrm{MMBtu}]$

$H R_{g} \quad$ Heat rate [MMBtu/MWh]

$P_{g}^{\max } \quad$ Generator capacity upper bound [MW]

$P_{r, t}^{\max } \quad$ Hourly renewable resource: production upper bound [MW]

$C^{e s} \quad$ ESS capacity investment cost $[\$ / M W h-y r]$

$C^{p c} \quad$ ESS power conversion investment cost $[\$ / \mathrm{MW}-\mathrm{yr}]$

$C^{o m, e s} \quad$ ESS fixed O\&M cost [\$/MW installed]

$C^{d} \quad$ ESS discharge cost [\$/MWh]

$\eta \quad$ Roundtrip efficiency for ESS

$C_{j}^{i n v} \quad$ Transmission investment cost [\$/yr]

$F_{l}^{\max } \quad$ Line real power flow capacity [MW] 


$\begin{array}{ll}B_{l} & \text { Susceptance on line [p.u.] } \\ P_{b, t, s}^{d} & \text { Demand at bus [MW] } \\ C^{u e} & \text { Cost penalty for unserved energy [\$/MWh] } \\ R P S & \text { Renewable Portfolio Standard target [\%] } \\ C^{n c} & \text { RPS noncompliance penalty [\$/MWh] } \\ M & \text { Big M parameter for disjunctive constraints } \\ \sigma_{s} & \text { Probabilistic weighting of a scenario } \\ 3.1 .3 . & \text { Investment (First Stage) Variables } \\ k_{b}^{e s} & \text { Integer investment for storage capacity } \\ k_{b}^{p c} & \text { Integer investment for power conversion } \\ x_{n, b}^{g} & \text { Integer variable indicating thermal generator builds } \\ x_{r, b}^{r} & \text { Continuous variable indicating renewable generator builds } \\ x_{j} & \text { Binary variable indicating transmission line builds } \\ 3.1 .4 . & \text { Operational (Second Stage) Variables } \\ p_{g, b, t, s} & \text { Generator dispatch at bus [MW], } \geq 0 \\ p_{b, t, s}^{u e} & \text { Load shed at bus [MW], } \geq 0 \\ f_{l, t, s} & \text { Flow on line [MW] } \\ \theta_{b, t, s} & \text { Phase angle at bus [radians] } \\ s_{b, t, s} & \text { Energy level in ESS at bus [MWh], } \geq 0 \\ r_{b, t, s}^{c} & \text { Charging of ESS at bus [MW], } \geq 0 \\ r_{b, t, s}^{d} & \text { Discharging of ESS at bus [MW], } \geq 0 \\ b_{b, t, s}^{r} & \text { Binary variable indicating ESS mode } \\ p^{n c} & \text { RPS noncompliance [MWh], } \geq 0\end{array}$

\subsection{Model Formulation}

We now introduce our co-optimization model considering a centralized planner, capturing investment in thermal and renewable generators, ESS, and trans- 
mission lines 3 This model reflects a two-stage decision process, in which investment decisions are made in the first stage. Second stage decisions are then based on economic dispatch, where the investment decisions from the first stage are tested against operating conditions representing different days.

We use a generic representation of an ESS, with the energy capacity (MWh stored) and power conversion (MW input/output) components decoupled. This approach allows the model to determine the optimal power-to-energy ratio for the system, similar to the formulation introduced in [47. Such a representation is sufficiently flexible to enable specification of a broad portfolio of real ESS, including pumped-hydro storage, compressed air storage, and batteries.

Total system costs are broken into first stage costs $\left(C^{f s}\right)$, which include costs associated with investment in new generators, transmission lines, and ESS, and second stage costs $\left(C^{s s}\right)$, which include operational costs associated with all assets, in addition to penalties associated with RPS non-compliance and unserved energy. Formally, these costs are computed as follows:

$$
\begin{aligned}
C^{f s}= & \sum_{n \in \mathcal{N}, b \in \mathcal{B}} C_{n}^{i n v} x_{n, b}^{g}+\sum_{j \in \mathcal{J}} C_{j}^{i n v} x_{j}+\sum_{b \in \mathcal{B}}\left(C^{e s} k_{b}^{e s}+C^{p c} k_{b}^{p c}\right) \\
C_{s}^{s s}= & \sum_{g \in \mathcal{G}, b \in \mathcal{B}, t \in \mathcal{T}}\left(C_{g}^{f u e l} H R_{g}+C_{g}^{\text {vom }}\right) p_{g, b, t, s} \\
& +\sum_{e \in \mathcal{E}} C_{e}^{f o m} P_{e}^{\text {max }}+\sum_{n \in \mathcal{N}, b \in \mathcal{B}} C_{n}^{f o m} P_{n}^{\text {max }} x_{n, b}^{g} \\
& +\sum_{b \in \mathcal{B}, t \in \mathcal{T}} C^{d} r_{b, t, s}^{d}+\sum_{b \in \mathcal{B}} C^{o m, e s} k_{b}^{p c}+\sum_{b \in \mathcal{B}, t \in \mathcal{T}} C^{u e} p_{b, t, s}^{u e}+C^{n c} p^{n c}
\end{aligned}
$$

\footnotetext{
${ }^{3}$ As discussed in [46], this is equivalent to a decentralized market model with perfect competition and nodal pricing. However, more realistic assumptions can be made. For instance, the model could be modified to consider market power of generation firms and ESS investors. Existing formulations that consider these features have been proposed in [31, 32, 33. Furthermore, as Sioshansi points out, ownership of ESS and market structure can affect the competitive equilibrium and social welfare [40. However, modeling a market where generators have market power would require a much more complicated model than the one used in this article, whose implementation is beyond the scope of our research.
} 
Our optimization model is then given by:

$\min C^{f s}+8760 \sum_{s \in \mathcal{S}} \sigma_{s} C_{s}^{s s}$

subject to

$$
\begin{array}{lrl}
\sum_{l(:, b) \in \mathcal{L}} f_{l, t, s}-\sum_{l(b,:) \in \mathcal{L}} f_{l, t, s}+\sum_{g \in \mathcal{G}} p_{g, b, t, s} & \\
\quad+\left(r_{b, t, s}^{d}-r_{b, t, s}^{c}\right)+p_{b, t, s}^{u e}=P_{b, t, s}^{d} & \forall b \in \mathcal{B}, t \in \mathcal{T}, s \in \mathcal{S}(2) \\
p_{e, b, t, s} \leq P_{e}^{\text {max }} & \forall e \in \mathcal{E}, b \in \mathcal{B}, t \in \mathcal{T}, s \in \mathcal{S}(3) \\
\left|f_{l, t, s}\right| \leq F_{l}^{\text {max }} & \forall l \in \mathcal{L}, t \in \mathcal{T}, s \in \mathcal{S}(4) \\
f_{l, t, s}=B_{l}\left(\theta_{b, t, s}-\theta_{b^{\prime}, t, s}\right) & \forall l\left(b, b^{\prime}\right) \in \mathcal{L}, t \in \mathcal{T}, s \in \mathcal{S}(5)
\end{array}
$$

For new generators $\mathcal{N} \subseteq \mathcal{G}$ and transmission lines $\mathcal{J} \subseteq \mathcal{L},(3)$ and (5) are modeled as disjunctive constraints, as in 48 . We define capacity (7) based on the solar or wind resources available in each time period, $P_{r, t}^{\max }$, in contrast to the time-independent $P_{g}^{\max }$ for new thermal generators:

$$
\begin{array}{lr}
p_{n, b, t, s} \leq x_{n, b}^{g} P_{g}^{\max } & \forall n \in \mathcal{N} \backslash R, b \in \mathcal{B}, t \in \mathcal{T}, s \in \mathcal{S}(6) \\
p_{r, b, t, s} \leq x_{r, b}^{r} P_{r, t}^{\max } & \forall r \in \mathcal{R}, b \in \mathcal{B}, t \in \mathcal{T}, s \in \mathcal{S}(7) \\
\left|f_{j, t, s}-B_{l}\left(\theta_{b, t, s}-\theta_{b^{\prime}, t, s}\right)\right| \leq M\left(1-x_{j}\right) & \forall j\left(b, b^{\prime}\right) \in \mathcal{J}, t \in \mathcal{T}, s \in \mathcal{S}(8)
\end{array}
$$

Next, we add ESS modeling components. Response times for ESS, which range from milliseconds to many minutes depending on specific technology, are not considered in our formulation. In the formulation of ESS, we use a binary variable $b_{b, t, s}^{r}$ to indicate whether the ESS unit is charging or discharging. However, including such binary variables increases the computational difficulty of our model, which may not be desirable for larger case studies. In Appendix A we investigate the impact of not including such binary variables. We assume that roundtrip efficiency is evenly distributed across charging and discharging 
modes, with $\eta^{c}=\eta^{d}=\sqrt{\eta}$. Our ESS model is then given as:

$$
\begin{array}{rlrl}
s_{b, t, s} & =s_{b, t-1, s}+\Delta t\left(\eta^{c} r_{b, t, s}^{c}-r_{b, t, s}^{d} / \eta^{d}\right) & & \forall b \in \mathcal{B}, t \in \mathcal{T}, s \in \mathcal{S} \\
s_{b, t, s} \leq k_{b}^{e s} & & \forall b \in \mathcal{B}, t \in \mathcal{T}, s \in \mathcal{S}(10) \\
r_{b, t, s}^{c} \leq k_{b}^{p c} & \forall b \in \mathcal{B}, t \in \mathcal{T}, s \in \mathcal{S}(11) \\
r_{b, t, s}^{d} \leq k_{b}^{p c} & \forall b \in \mathcal{B}, t \in \mathcal{T}, s \in \mathcal{S}(12) \\
r_{b, t, s}^{c} \leq M \cdot b_{b, t, s}^{r} & \forall b \in \mathcal{B}, t \in \mathcal{T}, s \in \mathcal{S}(13) \\
r_{b, t, s}^{d} \leq M \cdot\left(1-b_{b, t, s}^{r}\right) & \forall b \in \mathcal{B}, t \in \mathcal{T}, s \in \mathcal{S}(14)
\end{array}
$$

We make our model separable by day by modifying $(9)$, so that the last hour of each representative day coincides with the first hour of the same day rather than that of the following day. We do this because our load data only provides days that are representative of "typical" loads across the sampled years (see Section 4), so five sampled days are not actually consecutive in time. We also note that, because daily over-production is the key challenge for renewable integration, intraday load shifting via ESS is seen as more important than interday shifting [12. A similar formulation is presented in [37]:

$$
s_{b, t=1, s}=s_{b, t=T, s}+\Delta t\left(\eta^{c} r_{b, t=1, s}^{c}-r_{b, t=1, s}^{d} / \eta^{d}\right) \quad \forall b \in \mathcal{B}, s \in \mathcal{S}
$$

Finally, we have the RPS constraint, which enforces a lower bound on the amount of annual energy production that is met by qualifying renewables [46]:

$$
\sum_{\substack{r \in \mathcal{R}, b \in \mathcal{B}, t \in \mathcal{T}, s \in \mathcal{S}}} \sigma_{s} p_{r, b, t, s}+p^{n c} \geq R P S \sum_{\substack{g \in \mathcal{G}, b \in \mathcal{B}, t \in \mathcal{T}, s \in \mathcal{S}}} \sigma_{s} p_{g, b, t, s}
$$

Due to the long-term planning nature of this model, we do not include features such as unit commitment variables and constraints, forced outage rates, ramp rates, and lower limits on power output. We acknowledge that these assumptions limit our conclusions, because it is well known that both the intermittency and unpredictability of renewables present operational challenges that can only be captured when considering the features mentioned above [10. However, a model with such a level of detail would result in a much more challenging 
optimization problem than the one we consider in this study. 4 Furthermore, such a model would likely require the utilization of a more sophisticated solution technique for large-scale problems than the one we use in this article, such as Benders decomposition [51] or Progressive Hedging [52].

Other promising solution approaches for large-scale or nonlinear applications are heuristics. Some of the most popular heuristics applied to planning problems include particle swarm optimization 53, 54, greedy randomized search [55], sensitivity analysis [56, and genetic algorithms [57]. Although there is no guarantee that these heuristics will indeed find a global optimum, they often provide high quality solutions that could suffice for industrial applications in much shorter times than an algorithm such as branch and cut. For instance, $\mathrm{AC}$ transmission planning is a clear example of a highly nonlinear and nonconvex problem where a heuristic might perform much better than an interior point method [27. However, the application of decomposition techniques or solution heuristics is beyond the scope of this paper, and we leave it as a subject of future research. Further, our objective in this paper is to first fully quantify the impact of co-optimization, which requires an exact solution method.

We implement the above model using the Pyomo 4.2 algebraic modeling language and library [58. All experimental instances are solved using Gurobi 6.5.0 on an quad-core workstation with $16 \mathrm{~GB}$ of RAM. The two-stage stochastic MILP is solved to a $0.1 \%$ optimality gap, unless otherwise noted. All discrete decision variables in the model are then fixed, and the model is re-solved as a linear program (LP) to recover dual information, i.e., locational marginal prices (LMPs) and REC prices.

\footnotetext{
${ }^{4}$ Previous studies have discussed the tradeoffs associated with excluding different operating constraints in generation planning models [49] 50]. The authors of [49] find a $0.02 \%$ error in cost for models considering thermal generators when relaxing unit commitment variables and constraints.
} 


\section{Data}

We now describe the test network and associated data used for the numerical case study presented in Section 5

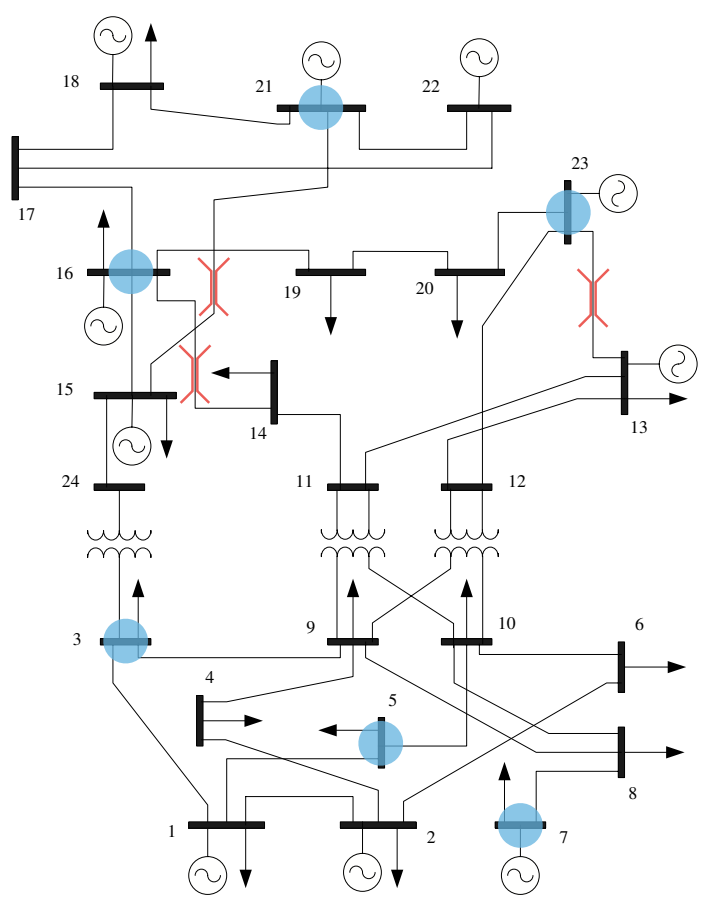

Figure 1: Diagram of the 24-bus IEEE Reliability Test System. The six buses available for renewable investment are highlighted in blue, each with different renewable resource profiles. The three transmission corridors with reduced line limits are also highlighted, in red. (Adapted from [59].)

Network. Our experimental results are based on the 24-bus IEEE Reliability Test System (RTS-96), which consists of 24 buses, 34 transmission lines, and 32 existing generators with an aggregate installed capacity of 3,405 MW 60]. Existing generators are partitioned into nine groups, based on fuel type and generation technology. The system is divided into two voltage areas. Following [59, we allow renewables to be sited at six buses $(3,5,7,16,21,23)$; 59 only considers wind generation, while we consider both wind and solar. To induce 
congestion, thermal limits along the three transmission corridors connecting bus pairs $(15,21),(14,16)$, and $(13,23)$ are reduced to $400 \mathrm{MW}, 250 \mathrm{MW}$, and 250 MW, respectively. A modified network schematic is shown in Figure1.

Demand and Renewable Profiles. Hourly demand, wind, and solar PV profiles were obtained from Munoz and Mills [61. These profiles are based on five years of utility data, normalized for demand growth. Wind and solar profiles provide maximum hourly output from a given unit of renewable capacity, though both wind and solar generators can be curtailed when needed. Each of the six buses with renewable generation are prescribed different wind and solar profiles to mimic spatial variability. We select the number of days to sample in advance. Following [61, we then identify the sample from 10,000 replicates that minimizes the sum of the square differences of the means, standard deviations, and correlations between the replicate and the full dataset. The authors of 61 argue that at least 50 representative days are necessary to capture the behavior of the original system. However, for our purposes using the synthetic RTS-96 test case, we only consider five representative days in order to maintain computational tractability.

\begin{tabular}{|c|c|c|c|c|c|}
\hline $\begin{array}{l}\text { Gen. } \\
\text { Group }\end{array}$ & $\begin{array}{l}P_{e}^{\max } \\
{[\mathrm{MW}]}\end{array}$ & $\begin{array}{c}C_{e}^{\text {fuel }} \\
\text { [\$/MMBtu] }\end{array}$ & $\begin{array}{c}C_{e}^{f o m} \\
{[\$ / \mathrm{MW}-\mathrm{yr}]}\end{array}$ & $\begin{array}{c}C_{e}^{v o m} \\
{[\$ / \mathrm{MWh}]}\end{array}$ & $\begin{array}{c}H R_{e} \\
{[\mathrm{MMBtu} / \mathrm{MWh}]}\end{array}$ \\
\hline U12 & 12 & 11.47 & 13,170 & 3.6 & 12,000 \\
\hline U20 & 20 & 16.53 & 7,040 & 15.5 & 14,500 \\
\hline U50 & 50 & - & 14,800 & 2.65 & - \\
\hline U76 & 76 & 2.26 & 51,400 & 7.22 & 12,000 \\
\hline U100 & 100 & 11.47 & 13,170 & 3.6 & 10,000 \\
\hline U155 & 155 & 2.26 & 51,400 & 7.22 & 9,700 \\
\hline U197 & 197 & 11.47 & 13,170 & 3.6 & 9,600 \\
\hline U350 & 350 & 2.26 & 51,400 & 7.22 & 9,500 \\
\hline U400 & 400 & 0.72 & 93,300 & 2.14 & 10,000 \\
\hline
\end{tabular}

Table 1: Existing generator operational cost parameters

Cost Data. Operations costs for existing generators are shown in Table 1 , and were derived using current fuel and O\&M cost data obtained from the U.S. 


\begin{tabular}{|l|c|c|c|c|c|c|}
\hline $\begin{array}{l}\text { Gen. } \\
\text { Type }\end{array}$ & $\begin{array}{c}P_{n}^{\text {max }} \\
{[\mathrm{MW}]}\end{array}$ & $\begin{array}{c}C_{n}^{\text {fuel }} \\
{[\$ / \mathrm{MMBtu}]}\end{array}$ & $\begin{array}{c}C_{n}^{\text {fom }} \\
{[\$ / \mathrm{MW}-\mathrm{yr}]}\end{array}$ & $\begin{array}{c}C_{n}^{\text {vom }} \\
{[\$ / \mathrm{MWh}]}\end{array}$ & $\begin{array}{c}H R_{n} \\
{[\mathrm{MMBtu} / \mathrm{MWh}]}\end{array}$ & $\begin{array}{c}C_{n}^{\text {inv }} \\
{[\$ / \mathrm{MW}-\mathrm{yr}]}\end{array}$ \\
\hline CC & 620 & 4.38 & 13,170 & 3.6 & 7.05 & 59,650 \\
$\mathrm{CT}$ & 85 & 4.38 & 7,040 & 15.45 & 10.85 & 43,970 \\
Nuc. & 2,234 & 0.72 & 93,280 & 2.14 & 9.612 & 292,100 \\
IGCC & 600 & 2.26 & 62,250 & 31.7 & 8.7 & 232,400 \\
PV & $0-1,500$ & - & 24,690 & - & - & 251,900 \\
Wind & $0-1,000$ & - & 39,550 & - & - & 144,000 \\
\hline
\end{tabular}

Table 2: New generator investment and operations cost parameters

Energy Information Agency [62, 63]. Capacities and costs for new generators are compiled from the same data and are shown in Table2. Investments in new transmission lines are limited to the 34 existing corridors of the RTS-96 test case. Transmission investment costs are derived from the line lengths specified in the IEEE RTS-96 [60, with a cost of $\$ 450,000 /$ mile-yr for $138 \mathrm{kV}$ lines and $\$ 950,000 /$ mile-yr for $230 \mathrm{kV}$ lines from [64].

ESS Data. ESS component costs can vary significantly, depending on the specific storage technology. Several surveys have compiled cost estimates and discuss the technical use cases for different technologies [13, 65. These costs have been annualized based on a 20 year lifespan, with a $5 \%$ discount factor. While traditional ESS such as pumped-hydro storage provide a cheap means of storing energy, they incur relatively high power conversion investment costs and low roundtrip efficiencies. In contrast, newer battery ESS technologies tend to have relatively high energy capacity investment costs and high roundtrip efficiencies.

${ }_{265}$ We begin to address this contrast with a sensitivity analysis in Appendix B.2. however, the main results presented in Section 5 will be based on our base ESS case with the parameters described in Table 3.

\begin{tabular}{|c|c|c|c|c|}
\hline $\begin{array}{c}C^{e s} \\
{[\$ / \mathrm{MWh}-\mathrm{yr}]}\end{array}$ & $\begin{array}{c}C^{p c} \\
{[\$ / \mathrm{MW}-\mathrm{yr}]}\end{array}$ & $\begin{array}{c}C^{\text {om,es }} \\
{[\$ / \mathrm{MW}-\mathrm{yr}]}\end{array}$ & $\begin{array}{c}C^{d} \\
{[\$ / \mathrm{MWh}]}\end{array}$ & $\begin{array}{c}\eta \\
{[\%]}\end{array}$ \\
\hline 4,000 & 80,000 & 5,000 & 5 & $81 \%$ \\
\hline
\end{tabular}

Table 3: Parameterization for base ESS case. 
In the experiments presented in this paper, we limit ESS capacity to 1,000 MWh/bus and only consider one ESS device type in a given experiment. However, we suggest that future studies incorporate a portfolio of ESS technologies, which can be straightforwardly represented in our model. Such optimal ESS portfolio investments (without generation and transmission expansion planning) have been studied in 39 .

\section{Results and Discussion}

We compare results obtained from a generation-and-transmission-expansion only (GTEP-only) model with those obtained from our fully co-optimized ESS model, to analyze the economic value of ESS co-optimization. We further compare these results to a sequential investment model — where generation and transmission expansion decisions are made first, then ESS decisions are made once these expansions decisions have been fixed.

In Section 5.1, we show that a significant proportion of the benefit from ESS investments in a bulk energy context come from generation and transmission investment deferrals, increasing the utilization of existing network assets. In contrast, operational savings results from arbitrage (load shifting and peak shaving) provide comparatively small benefits, most clearly demonstrated in our comparison with a sequential investment framework. We analyze the ESS sizing decisions in Section 5.2 , deriving average ESS unit costs on the network. Section 5.3 analyzes the endogenously derived REC prices to show the benefit of bulk ESS to meet increasing RPS targets. Finally, in Section 5.4 , we present a system-level hourly dispatch to show the behavior of bulk ESS.

A sensitivity analysis on fuel price, system demand, and ESS parameterization is presented in Appendix B to support these results.

\subsection{Total System Cost}

Our experiments indicate that the added option to invest in ESS in the fully co-optimized model significantly reduces annualized system cost for high RPS 


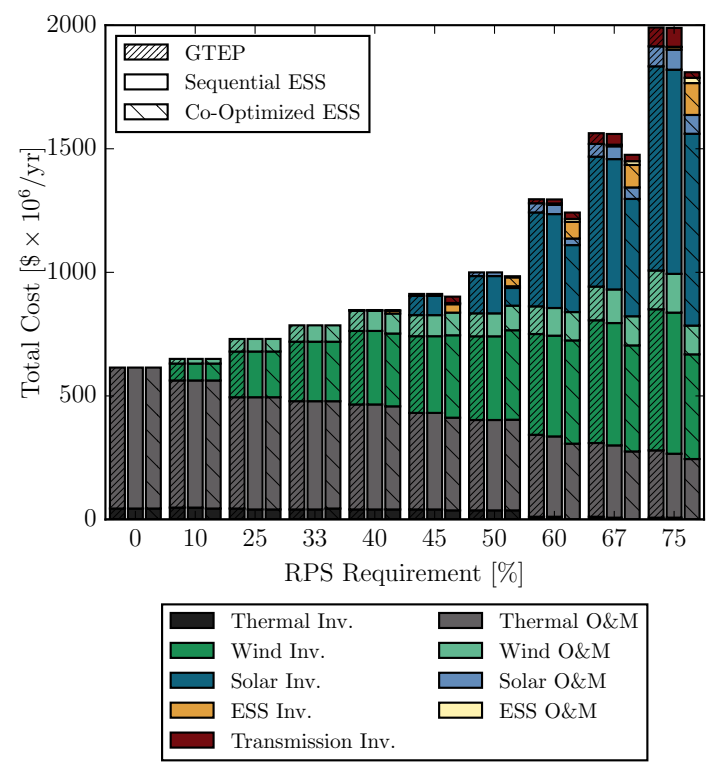

Figure 2: Annualized cost, showing the value of co-optimization of all three assets in comparison to a sequential investment framework (where generation and transmission decisions are made first followed by ESS investments) and the traditional GTEP-only decisions, over various RPS targets.

targets relative to either the GTEP-only or sequential investment decisions. Figure 2 breaks down the change in system costs, showing that the base ESS case saves up to $\$ 180$ million/yr in total system costs (9.1\% of GTEP-only costs) in the $75 \%$ RPS case, with correspondingly lower savings at lower RPS levels. In low RPS regimes, we see that there is little value for bulk energy services from cooptimized ESS. It is only at higher RPS levels, above $40 \%$ penetration, where cooptimized ESS comes into the market. In these cases, we see relative reductions in renewable capacity investments due to higher utilization of that capacity to meet the same penetration targets. In the $67 \%$ and $75 \%$ RPS targets, we also see transmission investment deferrals from co-optimized ESS. Since the IEEE RTS-96 network is relatively well-connected with limited congestion, we expect greater ESS value to be found in systems with tighter transmission constraints, as in 38 . 
In the sequential investment situation, ESS would provide value solely through operational savings (e.g. load shifting, balancing, and reductions in generator O\&M) [16, 36, 39. In Figure 2, the direct cost of sequential ESS investments are barely visible at any RPS target; however, we can see the indirect, operational cost savings at RPS targets above $60 \%$, where thermal O\&M costs begin to fall below the GTEP-only solution. In total, the savings from sequential ESS investments imply only $\$ 3$ million/yr in value from bulk energy services in this case study. Thus, the sequential model captures at most $1.7 \%$ of the $\$ 180$ million/yr savings from fully co-optimized bulk ESS.

\subsection{ESS Sizing and Siting}

\begin{tabular}{|c||c|c|c||c|c|c|}
\hline \multicolumn{1}{|c||}{ RPS } & \multicolumn{4}{c||}{ Co-Optimized } & \multicolumn{3}{c|}{ Sequential } \\
{$[\%]$} & {$[\mathrm{MW}]$} & {$[\mathrm{MWh}]$} & Buses & {$[\mathrm{MW}]$} & {$[\mathrm{MWh}]$} & Buses \\
\hline 0 & - & - & - & - & - & - \\
10 & - & - & - & - & - & - \\
25 & - & - & - & - & - & - \\
33 & - & - & - & - & - & - \\
40 & 100 & 850 & 13,23 & - & - & - \\
45 & 300 & 2,500 & $7,8,15,17,23$ & - & - & - \\
50 & 300 & 2,950 & $13-15,21,23$ & - & - & - \\
60 & 650 & 3,900 & $1,7,11,13,15,20,21$ & 50 & 300 & 14 \\
67 & 900 & 4,750 & $3,7,10,13,21,23,24$ & 50 & 450 & 14 \\
75 & 1,250 & 7,250 & $1,3,5,7-10,13$, & 100 & 600 & 14 \\
& & & $14,19,23,24$ & & & \\
\hline
\end{tabular}

Table 4: Built ESS capacity in each RPS scenario for the fully co-optimized model v. sequential investment framework.

In our co-optimization findings, we observe that the mean power-to-energy ratio across RPS targets is 1:6.3, with a mean annualized installed cost of $\$ 110,000 / \mathrm{MW}-\mathrm{yr}$ or $\$ 15,000 / \mathrm{MWh}-\mathrm{yr}$. These installed costs are very competitive with the generation and transmission investment costs prescribed in Section 4. Table 3 shows how ESS investments quickly increase with RPS targets, growing to $33 \%$ of peak system demand (MW) in the $75 \%$ target. At $75 \%$ RPS, 
ESS investments are made across half the buses in the system due to the constraint that no more than 1,000 MWh of ESS be sited at any location. In the presented case study, ESS investments are often made near or co-located with renewable generation. Further, co-optimized ESS is never co-located with new thermal generation (though sometimes with existing thermal), indicating that ESS and thermal generators provide redundant services in the face of significant renewables in terms balancing. However, we also note the limitations of the conclusions from this case study given the relatively homogenous test network and the lack of transmission losses in our model formulation.

In contrast, sequential ESS investments are very limited in both size and location across RPS targets. In these cases, ESS is only sited at bus 14, which is connected to renewable resources at bus 16 by one of the reduced transmission lines (see Figure 1) and relatively far from other generators). In contrast to the co-optimized solution, new combustion turbine (CT) generators are co-located with the sequential ESS investments at bus 14, indicating that the installed CT units are of relatively low value, and ESS is providing an additional balancing service at this bus.

\subsection{REC Pricing}

Our original motivation in this research was to investigate the contribution of ESS to meeting RPS requirements. Previous sections have discussed ESS investments and how they reduce overall system cost at various renewable penetration levels. We now focus on how ESS can specifically influence REC pricing associated with a desired renewable penetration level. REC prices correspond to the marginal cost of meeting an RPS target, which we compute as the change in total system cost that results from increasing the renewable target by one MWh 5 Figure 3 shows the evolution of the REC price at increasing RPS levels.

\footnotetext{
${ }^{5}$ In a convex model (e.g. a linear program), the REC prices are simply the dual variables associated with constraint 16. However, because our model includes binary variables, we estimate the REC prices using the definition of a shadow price [29].
} 
We observe the non-convexity of the REC price as a function of RPS targets, due to the lumpy nature of the investments.

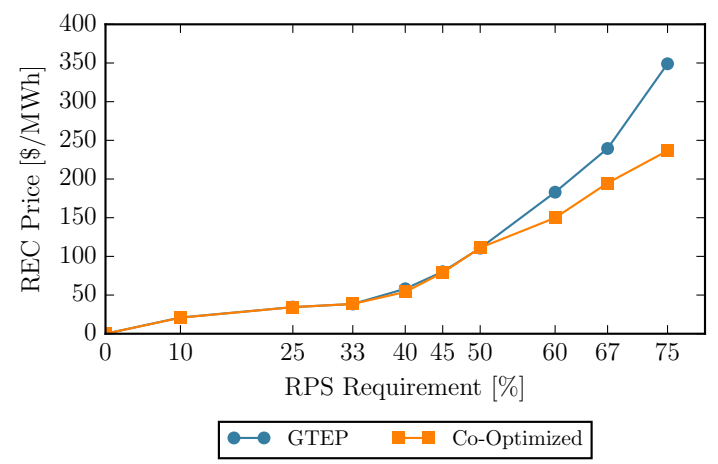

Figure 3: Endogenously derived REC prices for various RPS targets on the RTS-96 test network for the GTEP-only and the fully co-optimized solutions. The REC price describes the marginal increase in system cost to meet an incremental increase in the RPS target. Tick marks on the $\mathrm{x}$-axis correspond to RPS targets tested.

At renewable targets below $50 \%$, we do not see a significant reduction in the REC price due to the introduction of co-optimized ESS investments. We see a marginal decrease in REC prices at the $40 \%$ RPS target, but the gap closes at $45 \%$ and $50 \%$ before increasing again at very high RPS targets due to non-convexities in investment decisions. For the RPS targets of $60 \%$ and higher, we begin to see significant REC price reductions, consistent with our observations in Section 5.1 that co-optimized ESS leads to significant generation and transmission investment deferrals in addition to operational savings.

In the context of the marginal value of renewable capacity, Figure 4 shows the aggregate impact of co-optimized ESS investments on renewable dispatchability, which is directly related to the incremental cost of meeting renewable targets (i.e. the REC price). Only a very small fraction of renewable are curtailed below $50 \%$ penetrations. However, curtailment in the GTEP-only solution grows quickly with renewable penetration, leading to an increasing marginal cost to supply energy into the market. At very high RPS targets, we observe that sequential ESS investments provide almost no incremental benefit over the 
GTEP-only solution in terms of total energy dispatched from renewables. At $75 \%$ RPS, we see that the GTEP solution curtails $33 \%$ of total renewables $(25 \%$ of available wind and $42 \%$ of available solar), and the sequential solution also curtails $33 \%$ of total renewables (33\% of each type). In contrast, co-optimized ESS leads to lower overall renewable capacity investments as well as lower curtailment, curtailing only $20 \%$ of installed resources (15\% and $25 \%$ in wind and solar, respectively).
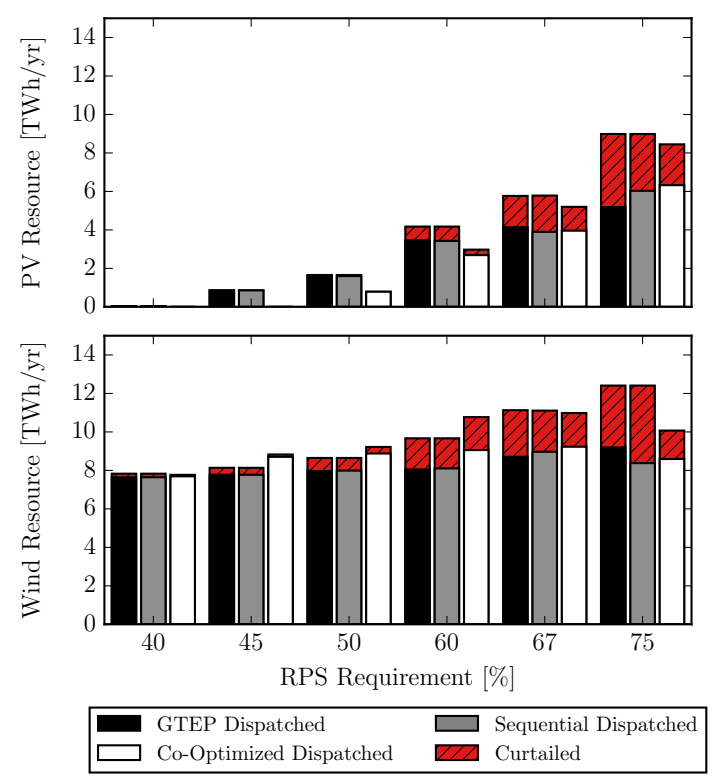

Figure 4: Available wind and solar resources dispatched and curtailed at various high RPS levels. In the sequential ESS solution, the available renewable resources (i.e. installed capacities) are equal to the GTEP-only solution, with marginal differences in dispatched renewables, since generation investments are fixed. In contrast, both capacity and total dispatch decisions differ significantly in the fully co-optimized solution.

\subsection{Hourly Dispatch}

Figure 4 highlighted the aggregate impact of co-optimized ESS on renewable energy: now, Figure 5 demonstrates how ESS behaves in each hour in the face of significant renewables. Here, the flexibility provided by co-optimized ESS allows the system operator to capture and shift significant renewable energy 
across time. The co-optimized dispatch clearly shows how spikes in renewable production are covered by ESS flexibility and moved to hours of low renewables. In contrast, only $50 \mathrm{MW}$ of ESS capacity are available in the sequential ESS solution, resulting in only marginal load shifting.

Further, and implicitly, ESS can be seen to assist thermal generators with load following services. With co-optimized ESS, ramps are not fully eliminated, but are reduced when there is excess renewable production early in the day to be discharged in the peak periods. In the second representative day in Figure 5 (a relatively high load day), the thermal ramp with co-optimized storage is still steep owing to the limited amount of renewables earlier in the day. In the third representative day, a low-demand day, there is a significant drop-off in wind production that requires thermal generators to ramp up for only a few hours to provide balancing services in the GTEP-only and sequential solutions; however, the co-optimized ESS is able to capture a spike in renewables early in the day (that would otherwise be curtailed without ESS) to provide balancing. Since our model formulation does not explicitly model generator ramping or unit commitment constraints, we expect that the value of ESS for providing balancing services to be consistently higher in real systems subject to these technical constraints.

\section{Conclusions and Policy Implications}

Our results indicate that co-optimizing ESS investments can be a costeffective investment mechanism to achieving compliance with high RPS targets. We demonstrate that ESS investments can economically provide bulk energy services to systems with increasing renewables penetration levels, including load shifting/peak shaving, and can facilitate investment deferrals. Our numerical experiments show savings of up to $\$ 180$ million/yr (9.1\%) in total system costs for the highest RPS target considered when co-optimizing ESS. The introduction of co-optimized ESS increases operational flexibility and enables better energy balancing across the network, lowering REC prices for RPS compliance and re- 


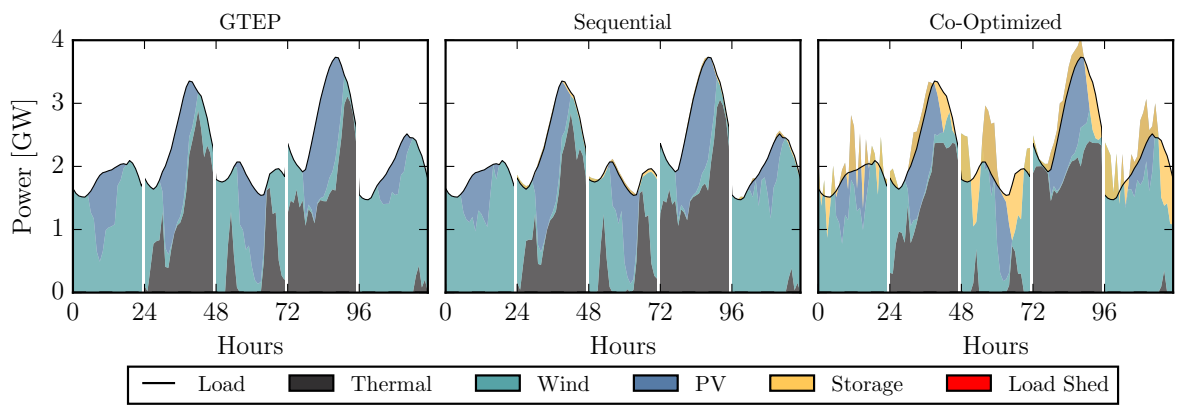

Figure 5: Hourly production over five sampled days for a $67 \%$ RPS level in our GTEPonly model (left), sequential ESS investments (middle), and fully co-optimized ESS (right). ESS investments made in the sequential setting provide only marginal dispatchable power, while fully co-optimized ESS capacity is able to provide significant load shifting across all representative days.

ducing renewable curtailment. However, the vast majority of the value of our co-optimization framework is derived from investment deferrals. In contrast, we find that making ESS investment decisions after generation and transmission investments have been fixed results in just $\$ 3$ million/yr in cost savings via operational benefits. Plainly, we find that it is only by considering generation, transmission, and ESS simultaneously that we are able to extract the full value of bulk ESS investments. These findings are contrary to [16, 36, 39, who find sufficient operational savings to induce beneficial ESS investments in cases where generation and transmission capacities are considered fixed.

We also find that the incremental need for ESS capacity grows quickly at high RPS levels. The optimal bulk ESS capacity reaches $1.25 \mathrm{GW}$ at $75 \%$ RPS levels on our test network, corresponding to $33 \%$ of peak system demand and $21 \%$ of total renewables capacity. Such ESS penetration levels pose a challenge in practice, as just $60 \mathrm{MW}$ of ESS capacity was installed in the U.S. market (where non-coincidental peak demand is on the order of $700 \mathrm{GW}$ [66]) in Q3 2015, though it is estimated that ESS deployments could scale to over $1 \mathrm{GW} / \mathrm{yr}$ by 2020 [67. 
Although our model ignores important features that become particularly relevant at high renewable targets, such as unit commitment state, unit ramping limits, and the stochastic nature of wind and solar production, our results highlight the need for models that explicitly and concurrently consider the capacities of all generation, transmission, and storage assets in the system as variables - as is the case in real-world power systems. Such co-optimization models are necessary for appropriately gauging the full economic value of bulk energy services from various energy storage technologies.

A direct application of the planning framework proposed in this article is in vertically integrated utilities, where a single planning authority makes all investment decisions. Some examples of these include the Bonneville Power Administration and the Tennessee Valley Authority in the US. Customers served by these utilities could greatly benefit if planners selected infrastructure to meet renewable targets co-optimizing all assets simultaneously, instead of sequentially as they do in practice.

In deregulated markets, such as the California ISO, the PJM Interconnection, and the New England ISO in the US, as well as the power sectors in Australia, Korea, Japan, Scandinavia, Chile, New Zealand, and Spain, the planning of generation, transmission, and ESS investments is done by separate entities. For those markets, the results from the co-optimization model proposed would only provide an upper bound on the cost savings that could be attained if transmission planners and private investors in generation and ESS worked collaboratively. Another potential application is in deregulated markets where there is nearly perfect competition and nodal pricing. In those markets, a proactive or anticipative transmission planner could utilize our co-optimization model to select transmission investments taking into consideration the response of private investors in generation and ESS capacity.

Finally, a challenge that remains open is the application of the proposed framework to larger and more realistic networks. Further work will go into applying this stochastic modeling framework in a high performance computing environment to test more representative days and larger networks. 


\section{Acknowledgments}

The research in this article was supported by FONDECYT \#11150029,

460 CONICYT/FONDAP/15110019 (SERC-CHILE), Basal Project FB0008, and the U.S. Department of Energy's Office of Science through the Advanced Scientific Computing Research program, under contract number KJ0401000, project title "Multifaceted Mathematics for Complex Energy Systems." Sandia National Laboratories is a multi-program laboratory managed and operated by 465 Sandia Corporation, a wholly owned subsidiary of Lockheed Martin Corporation, for the U.S. Department of Energy's National Nuclear Security Administration under Contract DE-AC04-94-AL85000. 


\section{Appendix A. ESS Charging State Indicator Variables}

Similar to [41, our formulation explicitly prevents ESS at each bus from

470 the use of the binary variables $b_{b, t, s}^{r}$. This phenomenon can occur in models that do not track charging and discharging state when there are sufficiently negative LMPs, resulting in excess energy being "burned off" through ESS inefficiency. However, in practice such operational behavior is unrealistic, and if solving the extensive form of our planning model for a realistic network will be 


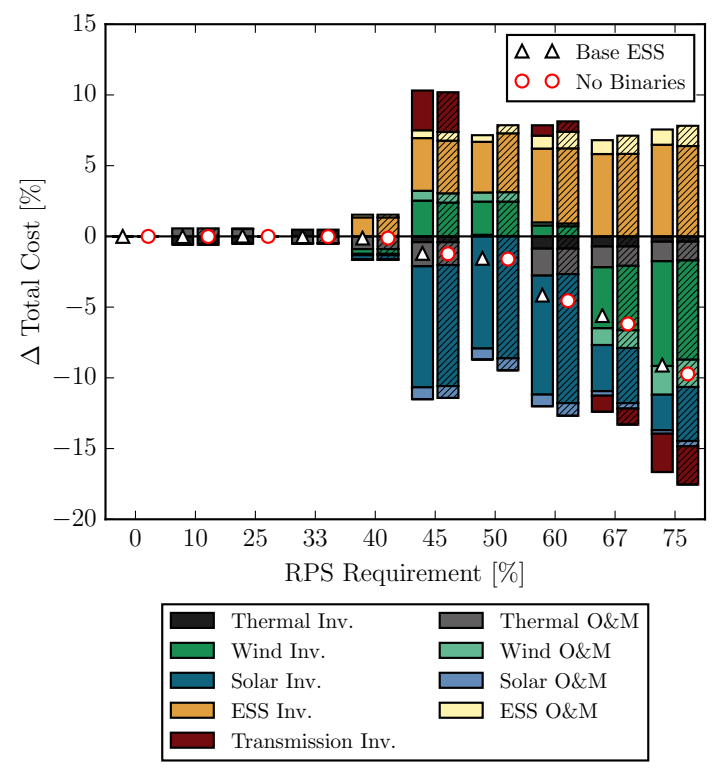

Figure A.6: Comparison of total costs for our base ESS case optimization model with and without charging mode indicators, $b_{b, t, s}^{r}$, showing only marginal impacts on total cost in all RPS targets for the case study presented in this paper. The higher ESS O\&M costs are associated with simultaneous charging/discharging behavior.

computationally intensive. Being able to relax the binaries variables could allow direct application of decomposition algorithms that require convexity of the operations (second-stage) problem, such as [51. In cases where the relaxation could result in significant errors, an alternative decomposition method that does not require convexity could be employed, such as [52].

\section{Appendix B. Sensitivity Analyses}

In this section, we present various sensitivity analyses on both system-level and ESS-specific parameters. While these findings are not a comprehensive analysis of all possible system parameters, they serve to support the key findings presented in Section 5 . 


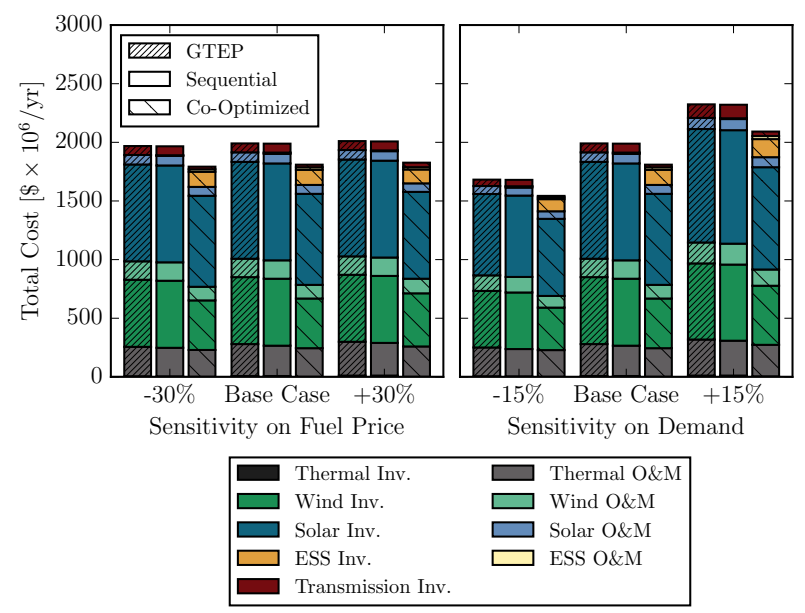

Figure B.7: Sensitivity analysis for fuel price (left) and demand (right) at $75 \%$ renewables penetration. Fuel price has only a minor impact on system cost, while varying demand noticeably changes system cost. However, across all sensitivities, co-optimized ESS shows significant cost savings over GTEP-only and sequential ESS investments.

\section{Appendix B.1. Fuel Price and Peak Demand}

Here, we present a sensitivity study for two key system parameters: fuel price, $C_{g}^{f u e l}$, and demand, $P_{b, t, s}^{d}$. We vary fuel prices by $\pm 30 \%$ from the base values in Tables 1 and 2 . For peak demand, we vary demand by $\pm 15 \%$ from the 4,600 MW peak in the base case. While both cases were performed across the original range of renewable penetrations ( $0 \%$ to $75 \%$ ), for the sake of conciseness, we present numerical results for only the highest case, $75 \%$. In both sensitivities, co-optimized ESS continues to provides significant savings over either the GTEP-only or sequential investment framework, in each case saving close to $9 \%$ in total system costs at renewables level of $75 \%$-in line with our main results.

In the case of fuel price, Figure B.7 shows that a $30 \%$ fluctuation in fossil fuel prices has a minimal effect on total cost, due to the low share of thermal generators on the system. REC prices for the $30 \%$ fuel price sensitivities were within $\$ 10 / \mathrm{MWh}$ of the base case values plotted in Figure 3 We observe a direct relationship between system demand and system cost. A $15 \%$ change 
in demand leads to approximately $15 \%$ changes in annualized cost. In the sensitivity on demand, we further observe that co-optimized ESS provides a cushion against the marginal cost of meeting stringent renewables targets. In the face of varying system demand, REC prices for the GTEP-only and sequentiallyinvested ESS vary by over $\$ 40 / \mathrm{MWh}$, while REC prices for the co-optimized ESS vary by less than $\$ 5 /$ MWh. Based on our main findings as in Figure 4 . lower renewables curtailment likely explains a significant portion of these savings from co-optimization.

\section{Appendix B.2. "Battery" ESS Parameters}

In this section, we present a second parameterization of the ESS units as a brief sensitivity of ESS costs depending on the technology considered. In the "battery" ESS case, we mimic a higher efficiency, higher power-to-energy ratio technology, such as lithium-ion batteries that have become increasingly popular for grid-scale storage, with the characteristics described in Table B.5. In this case, the investment cost of the energy component is much higher relative to the power conversion equipment, as described in [13, 65].

\begin{tabular}{|c|c|c|c|c|}
\hline $\begin{array}{c}C^{e s} \\
{[\$ / \mathrm{MWh}-\mathrm{yr}]}\end{array}$ & $\begin{array}{c}C^{p c} \\
{[\$ / \mathrm{MW}-\mathrm{yr}]}\end{array}$ & $\begin{array}{c}C^{\text {om,es }} \\
{[\$ / \mathrm{MW}-\mathrm{yr}]}\end{array}$ & $\begin{array}{c}C^{d} \\
{[\$ / \mathrm{MWh}]}\end{array}$ & $\begin{array}{c}\eta \\
{[\%]}\end{array}$ \\
\hline 56,000 & 16,000 & 5,000 & 7 & $95 \%$ \\
\hline
\end{tabular}

Table B.5: Parameterization for "battery" ESS case.

With higher investment and O\&M costs associated with the "battery" parameterization, we see a significantly lower investment in ESS capacity, as shown in Table B.6. In this case, ESS investments are most often co-located with renewable generation with a higher power-to-energy ratio of 1:1.9, suggesting a shift toward power services rather than bulk energy shifting. Figure B.8 shows the relative cost savings over the standard GTEP model and compares these savings to the co-optimize solution in our base ESS case first presented in Section 5.1. The result is lower cost savings when compared to our base co-optimization solution, up to $2.6 \%$ of the GTEP-only system cost (versus up to $9.1 \%$ in the 


\begin{tabular}{|c||c|c|c|}
\hline \multicolumn{1}{|c||}{ RPS } & \multicolumn{3}{c|}{ Battery ESS } \\
{$[\%]$} & {$[\mathrm{MW}]$} & {$[$ MWh $]$} & Buses \\
\hline 0 & - & - & - \\
10 & - & - & - \\
25 & - & - & - \\
33 & - & - & - \\
40 & - & - & - \\
45 & - & - & - \\
50 & - & - & - \\
60 & 150 & 150 & 13,14 \\
67 & 250 & 500 & $5,7,14$ \\
75 & 600 & 1,350 & $3,5,7,14$ \\
\hline
\end{tabular}

Table B.6: Built ESS capacity in each RPS scenario, for co-optimized "battery" ESS case.

base case). However, the co-optimized solution values battery ESS higher than the sequential framework, which does not invest in any ESS for any RPS target due to the high cost. We again observe that the majority of cost savings is associated with investment deferrals. Further, we observe that the "battery" ESS is still able to noticeably decrease the REC prices associated with different RPS targets, as shown in Figure B.9 below.

As our co-optimization formulation deals only in bulk energy services, fastresponding technologies will be consistently undervalued because other value streams, such as power and ancillary services, are not captured at the hourly timescale. However, we show that our conclusions for benefits of co-optimized ESS discussed in Section 5 are still applicable to ESS technologies with different characteristics.

\section{References}

[1] REN21, Renewables 2016: Global Status Report (2015). 


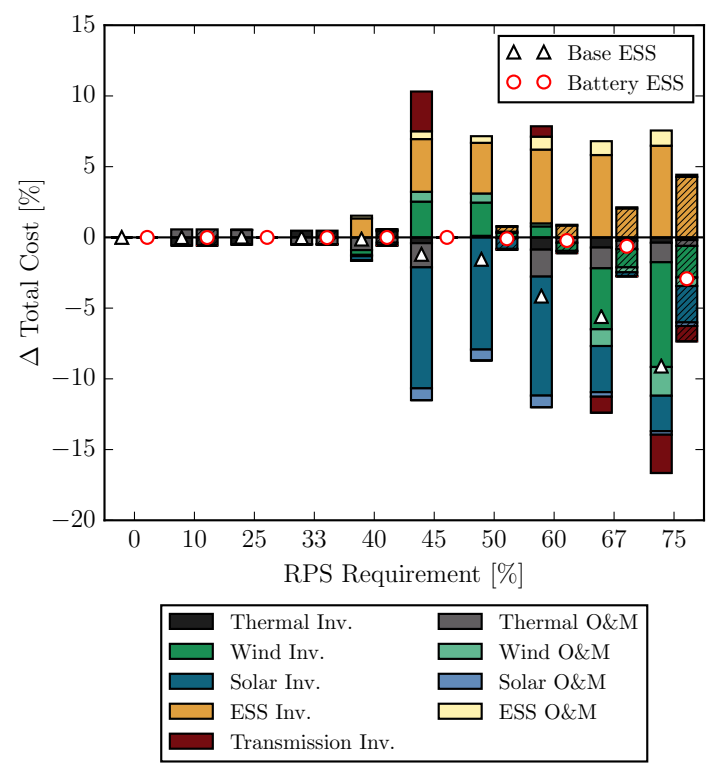

Figure B.8: Relative cost savings over GTEP-only solution, comparing impact of "base" and "battery" ESS parameterizations. Due to significantly higher investment and operating costs, less "battery" ESS capacity is built; however, there is still significant benefit derived by cooptimizing expensive ESS for bulk services, especially for high RPS targets.

[2] N.C. Clean Energy Technology Center, Database of State Incentives for Renewables and Efficiency (DSIRE) (2015).

URL http://www.dsireusa.org

¿ [3] California Legislature, Senate Bill No. 350, Clean Energy and Pollution Reduction Act of 2015 (2015).

URL https://leginfo.legislature.ca.gov/faces/billNavClient. xhtml?bill_id=201520160SB350

[4] T. Berry, M. Jaccard, The Renewable Portfolio Standard: Design Considerations and an Implementation Survey, Energy Policy 29 (2001) 263-277.

[5] G. Barbose, Renewables Portfolio Standards in the United States: A Status 575 Update, in: Renewable Energy Markets 2014, 2014, pp. 1-26.

[6] S. Sekar, B. Sohngen, The Effects of Renewable Portfolio Standards on 


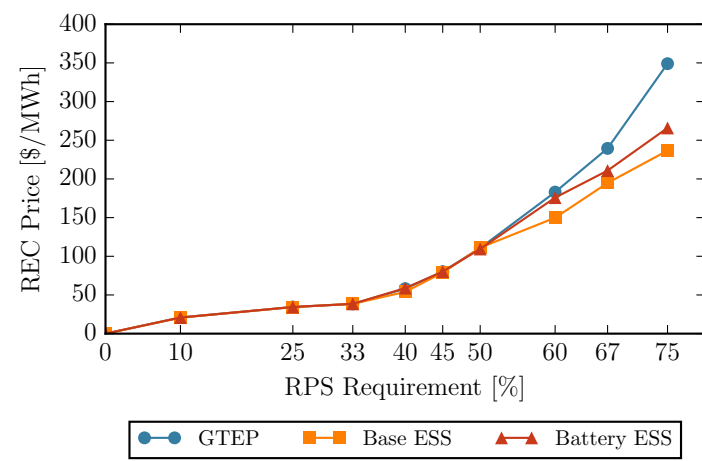

Figure B.9: Endogenously derived REC prices for various RPS targets on the RTS-96 test network. Here, we show the evolution of REC prices under the "battery" ESS regime, in addition to the results originally shown in Figure 3 While the "battery" ESS is more expensive, we still observe that REC prices increase more slowly than in the GTEP-only case.

Carbon Intensity in the United States, Tech. rep., Resources for the Future (Apr 2014).

[7] C. Yang, E. Williams, J. Monast, Wind Power: Barriers and Policy Solutions, Tech. rep., Climate Change Policy Partnership, Duke University (Nov 2008).

[8] G. Shrimali, S. Jenner, F. Groba, G. Chan, J. Indvik, Have State Renewable Portfolio Standards Really Worked?, in: 2012 Proc. of the United States Association for Energy Economics, 2012, pp. 1-20.

[9] D. Zafirakis, K. Chalvatzis, G. Baiocchi, G. Daskalakis, Modeling of Financial Incentives for Investments in Energy Storage Systems that Promote the Large-Scale Integration of Wind Energy, Applied Energy 105 (2013) 138154.

[10] C. I. S. Operator, What the Duck Curve Tells Us About Managing a Green 590 Grid, Tech. Rep. CommPR/HS/10.2013, California Independent System Operator (Oct 2013).

[11] N. Miller, M. Shao, S. Pajic, R. D'Aquila, Western Wind and Solar In- 
tegration Study Phase 1, Tech. Rep. NREL/SR-5D00-62906, GE Energy Management, National Renewable Energy Laboratory (Dec 2014).

[12] Energy + Environmental Economics, Investigating a Higher Renewables Portfolio Standard in California, Tech. rep., Energy + Environmental Economics (Jan 2014). URL https://ethree.com/documents/E3_Final_RPS_Report_2014_01_ 06_with_appendices.pdf

[13] A. Castillo, D. F. Gayme, Grid-Scale Energy Storage Applications in Renewable Energy Integration: A Survey, Energy Conversion and Management 87 (2014) 885-894.

[14] U.S. Federal Energy Regulatory Commission, Frequency Regulation Compensation in the Organized Wholesale Power Markets, Docket Nos. RM117-000 and AD10-11-000; Order No. 755 (Oct 2011).

[15] U.S. Federal Energy Regulatory Commission, Third-Party Provision of Ancillary Services; Accounting and Financial Reporting for New Electric Storage Technologies, Docket Nos. RM11-24-000 and AD10-13-000; Order No. 784 (Jul 2013).

[16] T. Das, V. Krishnan, J. McCalley, Assessing the Benefits and Economics of Bulk Energy Storage Technologies in the Power Grid, Applied Energy 139 (2015) 104-118.

[17] M. Abdurrahman, S. Baker, B. Keshavamurthy, M. Jacobs, Energy Storage as a Transmission Asset, Tech. rep., PJM Interconnection (2012). URL https://www.pjm.com/ /media/markets-ops/
advanced-tech-pilots/xtreme-power-storage-as-transmission. ashx

[18] B. Kaun, Cost-Effectiveness of Energy Storage in California: Application of the EPRI Energy Storage Valuation Tool to Inform the California Pub- 
lic Utilities Commission Proceeding R. 10-12-007, Tech. Rep. 3002001162, Electric Power Research Institute (Jun 2013).

[19] F. J. de Sisternes, J. D. Jenkins, A. Botterud, The Value of Energy Storage in Decarbonizing the Electricity Sector, Applied Energy 175 (2016) 368379.

${ }_{625}$ [20] California Legislature, Assembly Bill No. 2514, Energy storage systems (2010).

口 URL http://leginfo.legislature.ca.gov/faces/billNavClient. xhtml?bill_id=200920100AB2514

[21] G. Latorre-Bayona, R. D. Cruz, J. M. Areiza, A. Villegas, Classification of Publications and Models on Transmission Expansion Planning, IEEE Transactions on Power Systems 18 (2) (2003) 938-946.

[22] R. Hemmati, R.-A. Hooshmand, A. Khodabakhshian, Comprehensive Review of Generation and Transmission Expansion Planning, IET Generation, Transmission \& Distribution 7 (9) (2013) 955-964.

${ }_{635}$ [23] N. Alguacil, A. L. Motto, A. J. Conejo, Transmission Expansion Planning: A Mixed-Integer LP Approach, IEEE Transactions on Power Systems 18 (3) (2003) 1070-1077.

[24] L. Bahiense, G. C. Oliveira, M. Pereira, S. Granville, A Mixed Integer Disjunctive Model for Transmission Network Expansion, IEEE Transactions on Power Systems 16 (3) (2001) 560-565.

[25] Ö. Özdemir, F. D. Munoz, J. L. Ho, B. F. Hobbs, Economic Analysis of Transmission Expansion Planning with Price-Responsive Demand and Quadratic Losses by Successive LP, IEEE Transactions on Power Systems 31 (2) (2016) 1096-1107.

${ }_{645}^{64}$ [26] M. Rider, A. Garcia, R. Romero, Power System Transmission Network Expansion Planning Using AC Model, IET Generation, Transmission \& Distribution 1 (5) (2007) 731-742. 
[27] R.-A. Hooshmand, R. Hemmati, M. Parastegari, Combination of AC Transmission Expansion Planning and Reactive Power Planning in the Restructured Power System, Energy Conversion and Management 55 (2012) 26-35.

[28] S. Vajjhala, A. Paul, R. Sweeney, K. Palmer, Green Corridors: Linking Interregional Transmission Expansion and Renewable Energy Policies, Tech. rep., Resources for the Future (Mar 2008).

[29] F. D. Munoz, E. E. Sauma, B. F. Hobbs, Approximations in Power Transmission Planning: Implications for the Cost and Performance of Renewable Portfolio Standards, Journal of Regulatory Economics 43 (2013) 305-338.

[30] A. Perez, E. E. Sauma, F. D. Munoz, B. F. Hobbs, The Economic Effects of Interregional Trading of Renewable Energy Certificates in the WECC, The Energy Journal 7 (4) (2016) 267-295.

[31] F. H. Murphy, Y. Smeers, Generation Capacity Expansion in Imperfectly Competitive Restructured Electricity Markets, Operations research 53 (4) (2005) 646-661.

[32] E. E. Sauma, S. S. Oren, Proactive Planning and Valuation of Transmission Investments in Restructured Electricity Markets, Journal of Regulatory Economics 30 (3) (2006) 261-290.

[33] D. Pozo, E. E. Sauma, J. Contreras, A Three-Level Static MILP Model for Generation and Transmission Expansion Planning, IEEE Transactions on Power Systems 28 (1) (2013) 202-210.

[34] D. Ralph, Y. Smeers, The Invisible Hand for Risk Averse Investment in Electricity Generation, in: B. Chen (Ed.), Proceedings, 6th International Conference on Algorithmic Aspects in Information and Management, 2010, p. 12 .

[35] A. Ehrenmann, Y. Smeers, Generation Capacity Expansion in a Risky Environment: A Stochastic Equilibrium Analysis, Operations Research 59 (6) (2011) 1332-1346. 
[36] N. Li, K. W. Hedman, Economic Assessment of Energy Storage in Systems with High Levels of Renewable Resources, IEEE Transactions on Sustainable Energy 6 (3) (2015) 1103-1111.

[37] I. Konstantelos, G. Strbac, Valuation of Flexible Transmission Investment Options Under Uncertainty, IEEE Transactions on Power Systems 30 (2) (2015) 1047-1055.

[38] P. Denholm, R. Sioshansi, The Value of Compressed Air Energy Storage with Wind in Transmission-Constrained Electric Power Systems, Energy Policy 37 (8) (2009) 3149-3158.

[39] S. Wogrin, D. Gayme, Optimizing Storage Siting, Sizing, and Technology Portfolios in Transmission-Constrained Networks, IEEE Transacations on Power Systems 30 (6) (2015) 3304-3313.

[40] R. Sioshansi, When Energy Storage Reduces Social Welfare, Energy Economics 41 (2014) $106-116$.

[41] Z. Hu, F. Zhang, B. Li, Transmission Expansion Planning Considering the Deployment of Energy Storage Systems, in: IEEE Power and Energy Society General Meeting, 2012, pp. 1-6.

[42] D. Azari, S. S. Torbaghan, M. Gibescu, M. A. van der Meijden, The Impact of Energy Storage on Long Term Transmission Planning in the North Sea Region, in: North American Power Symposium (NAPS), 2014, pp. 1-6.

[43] M. Hedayati, J. Zhang, K. W. Hedman, Joint Transmission Expansion Planning and Energy Storage Placement in Smart Grid Towards Efficient Integration of Renewable Energy, in: IEEE Power and Energy Society T\&D Conference and Exposition, 2014, pp. 1-5.

[44] V. Krishnan, T. Das, Optimal Allocation of Energy Storage in a CoOptimized Electricity Market: Benefits Assessment and Deriving Indicators for Economic Storage Ventures, Energy 81 (2015) 175-188. 
[45] D. Zafirakis, K. J. Chalvatzis, G. Baiocchi, G. Daskalakis, The Value of Arbitrage for Energy Storage: Evidence from European Electricity Markets, Applied Energy.

[46] F. D. Munoz, B. F. Hobbs, J. L. Ho, S. Kasina, An Engineering-Economic Approach to Transmission Planning Under Market and Regulatory Uncertainties: WECC Case Study, IEEE Transactions on Power Systems 29 (1) (2014) 307-317.

[47] H. Pandžić, Y. Wang, T. Qiu, Y. Dvorkin, D. S. Kirschen, Near-Optimal Method for Siting and Sizing of Distributed Storage in a Transmission Network, IEEE Transactions on Power Systems 30 (5) (2015) 2288-2300.

[48] F. D. Munoz, B. F. Hobbs, S. Kasina, Efficient Proactive Transmission Planning to Accommodate Renewables, in: Power and Energy Society General Meeting, 2012 IEEE, 2012, pp. 1-7.

[49] S. Jin, A. Botterud, S. M. Ryan, Temporal Versus Stochastic Granularity in Thermal Generation Capacity Planning with Wind Power, IEEE Transactions on Power Systems 29 (5) (2014) 2033-2041.

[50] B. Palmintier, Flexibility in Generation Planning: Identifying Key Operating Constraints, in: Power Systems Computation Conference, 2014, pp. $1-7$.

[51] F. D. Munoz, B. F. Hobbs, J. P. Watson, New Bounding and Decomposition Approaches for MILP Investment Problems: Multi-area Transmission and Generation Planning Under Policy Constraints, European Journal of Operational Research 248 (3) (2016) 888-898.

[52] F. D. Munoz, J.-P. Watson, A Scalable Solution Framework for Stochastic Transmission and Generation Planning Problems, Computational Management Science 12 (4) (2015) 491-518. 
[53] H. Shayeghi, M. Mahdavi, A. Bagheri, Discrete PSO Algorithm Based Optimization of Transmission Lines Loading in TNEP Problem, Energy Conversion and management 51 (1) (2010) 112-121.

[54] Y.-X. Jin, H.-Z. Cheng, J.-y. Yan, L. Zhang, New Discrete Method for Particle Swarm Optimization and its Application in Transmission Network Expansion Planning, Electric Power Systems Research 77 (3) (2007) 227233.

[55] S. Binato, G. C. De Oliveira, J. L. De Araújo, A Greedy Randomized Adaptive Search Procedure for Transmission Expansion Planning, IEEE Transactions on Power Systems 16 (2) (2001) 247-253.

[56] G. Latorre-Bayona, I. J. Perez-Arriaga, Chopin, a Heuristic Model for Long-Term Transmission Expansion Planning, IEEE Transactions on Power systems 9 (4) (1994) 1886-1894.

[57] E. L. Da Silva, H. A. Gil, J. M. Areiza, Transmission Network Expansion Planning Under an Improved Genetic Algorithm, IEEE Transactions on Power Systems 15 (3) (2000) 1168-1174.

[58] W. E. Hart, C. Laird, J.-P. Watson, D. L. Woodruff, Pyomo-Optimization Modeling in Python, Vol. 67, Springer Science+Business Media, 2012.

[59] C. Ordoudis, P. Pinson, J. Morales, M. Zugno, An Updated Version of the IEEE RTS 24-bus System for Electricity Market and Power System Operation Studies, 31761 - Renewables in Electricity Markets (2014).

[60] R. Christie, C. Grigg, University of Washington Power Systems Test Case Archive, IEEE RTS 1996 [cited Jul 22, 2015]. URL https://www . ee . washington. edu/research/pstca/

[61] F. D. Munoz, A. D. Mills, Endogenous Assessment of the Capacity Value of Solar PV in Generation Investment Planning Studies, IEEE Transactions on Sustainable Energy 6 (2015) 1574-1585. 
[62] U.S. Energy Information Agency, Updated Capital Cost Estimates for Utility Scale Electricity Generating Plants, Tech. rep. (Apr 2013).

[63] U.S. Energy Information Agency, Short Term Energy Outlook, Tech. rep. (Jun 2015).

[64] PJM Interconnection, Transmission System Operations TO1, Interconnection Training Program, Presentation (2011).

[65] V. Viswanathan, M. Kintner-Meyer, P. Balducci, C. Jin, National Assessment of Energy Storage for Grid Balancing and Arbitrage, Phase II, Volume 2: Cost and Performance Characterization, Tech. Rep. PNNL-21388, Pacific Northwest National Laboratory (Sep 2013).

[66] U.S. Energy Information Agency, Annual Energy Review, Table 8.12a Elec-

a tric Noncoincident Peak Load and Capacity Margin: Summer Peak Period, 1986-2011 (September 2012).

a URL https://www.eia.gov/totalenergy/data/annual/showtext.cfm? $t=p t b 0812 a$

[67] GTM Research, U.S. Energy Storage Monitor: Q3 2015 Executive Summary, Presentation (Jan 2015).

[68] J. Cochran, M. Miller, M. Milligan, E. Ela, D. Arent, A. Bloom, Market Evolution: Wholesale Electricity Market Design for 21st Century Power Systems, Tech. rep., National Renewable Energy Laboratory (Oct 2013). 